\title{
Psychometric evaluation of the Portuguese Satisfaction with Family Life Scale
}

\author{
Marta Pinto da Costa ${ }^{*}$ (D) and Félix Neto
}

\begin{abstract}
The purpose of this study is to examine the psychometric properties of the Satisfaction with Family Life Scale (SWFLS) among Portuguese adolescents. This scale assesses a person's global evaluation of family satisfaction. The participants were 252 high school students from public schools in Lisbon, aged 15-19years ( $M=16.87 ; S D=1.21)$. Confirmatory factor analysis confirmed a one-factor model of the SWFLS among Portuguese adolescents. The SWFLS showed adequate psychometric properties, with good internal consistency. Subsequent analyses indicated that the SWFLS scores were related to a measure of family satisfaction, as well as wellbeing (life satisfaction, self-esteem) and current interpersonal functioning (social support and loneliness). These findings are interpreted as supporting the validity of the SWFLS. The findings of this research indicate that the Portuguese version of the SWFLS is a brief, psychometrically sound instrument to assess family life satisfaction.
\end{abstract}

Keywords: Confirmatory factor analysis, Family satisfaction, Portuguese adolescents, Test validation, Wellbeing

\section{Instrument}

The Satisfaction with Family Life Scale (SWFLS) was designed by Zabriskie and McCormick (2003) and measure of overall satisfaction with one's family. This scale comprises five items, each item is answered on a seven-level Likert scale (one $=$ strongly disagree to seven $=$ strongly agree).

\section{Introduction}

Happiness constitutes a core object of human existence. In recent decades, the amount of research on happiness or subjective wellbeing (SWB) has grown rapidly (Diener, Oishi, \& Lucas, 2015). As a result, a major issue is to understand what makes people feel happy or satisfied. The main focus of this study is to explore the psychometric characteristics of the Satisfaction with Family Life Scale (SWFLS) among Portuguese adolescents. Therefore, the theoretical and methodological background of the SWFLS will be briefly presented.

\footnotetext{
* Correspondence: marta_pintodacosta@hotmail.com

Faculdade de Psicologia e de Ciências da Educação, Universidade do Porto, Rua Alfredo Allen, 4200-135 Porto, Portugal
}

\section{Theoretical background}

\section{Life satisfaction}

Subjective wellbeing (SWB) is a key life outcome, defined as "people's evaluations of their lives - the degree to which their thoughtful appraisals and affective reactions indicate that their lives are desirable and proceeding well" (Diener et al., 2015, p. 234). In this line of thought, SWB is a multidimensional construct interlacing three core components: positive affect, negative affect, and satisfaction with life. The affective components embrace the presence of positive affect (such as joy and elation) and the absence of negative affect (such as sadness and envy).

Life satisfaction constitutes one of three major ways to assess societal quality of life, along with economic and social indicators (Diener, Oishi, \& Lucas, 2003). The study of satisfaction with life is important given its relationship with positive life outcomes, such as health and longevity, work and income, social relations, and societal benefits (Diener \& Ryan, 2009).

Satisfaction with life is the component of SWB that reflects the cognitive evaluation of how happy an individual is with his or her life. Shin and Johnson (1978) defined satisfaction with life as "a global assessment of a person's quality of life according to chosen criteria" (p. 478). This

(c) The Author(s). 2019 Open Access This article is distributed under the terms of the Creative Commons Attribution 4.0 International License (http://creativecommons.org/licenses/by/4.0/), which permits unrestricted use, distribution, and 
definition has inspired many researchers. For example, Diener and colleagues consider satisfaction with life as a judgmental process in which people evaluate the quality of their lives based on their own unique criteria (Diener, Sandvik, Seidlitz, \& Diener, 1993). It is intended to reflect a wide appraisal of a person's life as a whole, without differentiating between different domains. Satisfaction with life is considered stable under unchanging circumstances, but it is sensitive to changes in circumstances in people's lives (Diener, Inglehart, \& Tay, 2013).

This cognitive component of SWB encompasses global judgments of satisfaction with life and domain satisfactions, such as family, job, house, love, sex, migration, and recreation. The study of domain satisfactions is under-investigated in the field of SWB (Bardo \& Yamashita, 2014). In the present study, the focus is on a specific life domain, satisfaction with family life.

\section{Family satisfaction}

Schimmack, Diener, and Oishi (2002) suggested that family relations are among the most relevant sources of satisfaction with life. In Portugal, Ruiz (2010) found that the main predictor of satisfaction with life was satisfaction with family life. Past research showed that family satisfaction is considered an important area of study given its relation with health and quality of life, as well as with a broad set of family wellbeing measures, such as family cohesion, adaptability, communication, and overall family functioning (Poff, Zabriskie, \& Townsend, 2010).

Zabriske and Ward (2013) described a number of measures of family satisfaction, among them the Family Satisfaction by Adjectives Scale (FSAS) (Barraca, Yarto, \& Olea, 2000), which was previously adapted to the Portuguese culture (Nave et al., 2006). Since the FSAS primarily intends to measure the affective component of family satisfaction, in the present research, we sought to adapt, to the Portuguese culture, a measure of family satisfaction more concerned with the cognitive domain, that is, the SWFLS (Zabriske \& Ward, 2013).

Family satisfaction may be defined as "a conscious cognitive judgment of one's family life in which the criteria for the judgment are up to the individual" (Zabriske \& Ward, 2013, p. 249). According to this definition, Zabriskie and colleagues implemented the SWFLS (Zabriske \& Ward, 2013; Zabriskie \& McCormick, 2003), which was developed from the original Satisfaction with Life Scale (SWLS; Diener, Emmons, Larsen, \& Griffin, 1985). The SWLS has been adapted to many cultures (Diener et al., 2013), including the Portuguese culture (Neto, Barros, \& Barros, 1990). The SWLS includes five items to evaluate global satisfaction with life. A sample statement is "In most ways my life is close to my ideal." To assess satisfaction with family life, the term "family life" replaced "life" in all the items. Therefore, five similar items were built, such as "In most ways my family life is close to my ideal." The same design was used in other studies to develop other domain satisfactions, such as those to assess academic satisfaction (Neto \& Wilks, 2017; Vallerand \& Boissonnette, 1990), love satisfaction (Neto, 2005), sex satisfaction (Neto, 2012), migration satisfaction (Neto \& Fonseca, 2016), and job satisfaction (Neto \& Fonseca, 2018).

The SWFLS has shown consistent unifactorial structure and good internal consistency in past research in Australian, British, Canadian, New Zealand, and US samples (Zabriske \& Ward, 2013). Furthermore, criterion and construct validity were established. The scale may be used "with a wide variety of different populations and offers researchers, therapists, and practitioners the option of assessing perceptions of family satisfaction among children, adolescents, and adults" (Zabriske \& Ward, 2013, p. 455).

Besides the English-language version of the SWFLS, to the best of our knowledge, there is only a Spanish adaptation of the SWFLS (Caycho-Rodriguez et al., 2018; Schnettler et al., 2017). Thus, in this study, the Portuguese adaptation of the Satisfaction with Family Life Scale will be presented.

\section{The present study}

The present study has three objectives. Firstly, the internal structure of the SWFLS will be examined. To achieve this objective, a confirmatory factor analysis (CFA) will be used. It is expected that SWFLS scores will evidence a single underlying dimension in consonance with previous findings (Zabriske \& Ward, 2013; Zabriskie \& McCormick, 2003).

Secondly, the psychometric characteristics of the SWFLS will be examined. To achieve this objective, the internal consistency of the SWFLS will be calculated by means of Cronbach's alpha and the corrected item-factor correlations. According to Kline (2000), a Cronbach $\alpha$ between 0.70 and 0.90 is good and between 0.91 and 0.99 is excellent. It is expected that SWFLS evidence excellent internal consistency in consonance with previous studies (Zabriske \& Ward, 2013).

Thirdly, we will examine the relationship between the SWFLS and sociodemographic variables, namely gender and age. No significant gender differences (Diener \& Ryan, 2009; Glaesmer, Grande, Braehler, \& Roth, 2011; Myers \& Diener, 1995; Neto \& Pinto, 2015a; Neto \& Wilks, 2017) nor age differences (Bendayan, Blanca, Fernández-Baena, Escobar, \& Trianes, 2013; Glaesmer et al., 2011; Myers \& Diener, 1995; Neto \& Fonseca, 2018) are expected.

Fourthly, this study will examine the relationship between SWFLS scores and other constructs (FSAS, satisfaction with life, self-esteem, loneliness, and perceived social support) to assess the convergent and discriminant validities of the SWFLS. It is expected to 
find strong correlations between SWFLS and family life satisfaction by adjectives, satisfaction with life, and family support scores. Furthermore, it is expected that satisfaction with life family will predict life satisfaction beyond and above gender, age, and FSAS, in consonance with the "bottom-up" approach to satisfaction with family life (Brief, Butchner, George, \& Link, 1993).

\section{Scale development}

\section{Participants}

Participants were 252 high school students from public schools in Lisbon, Portugal. One hundred and thirty-two (52\%) of the participants were boys and 120 (48\%) were girls. Participants were between the ages of 15 and 19 $(M=16.87 ; \mathrm{SD}=1.21)$ and all respondents were of Portuguese nationality. As for their distribution along the three years of high school education, 108 (43\%) were in the 10th grade, $59(23 \%)$ in the 11th grade, and 85 (34\%) in the 12th grade.

Regarding the level of education of their mothers, 22\% had not completed high school, 37.6\% had completed high school, and $40.4 \%$ had attended tertiary education. The distribution of fathers' education is somewhat similar to that of the mothers' education, as $25.6 \%$ had not completed high school, $38.8 \%$ had completed high school, and $35.5 \%$ had attended tertiary education.

\section{Assessment instruments}

The instruments included a questionnaire comprising demographic information, as well as six instruments, previously adapted to Portuguese culture, barring the SWFLS.

1. Satisfaction with Family Life Scale (SWFLS). The SWFLS was designed by Zabriskie and McCormick (2003). This scale comprises five items (e.g., "In most ways my family life is close to my ideal" (see Table 1). Each item is answered on a seven-level Likert scale (one $=$ strongly disagree to seven $=$ strongly agree). Greater scores denote more satisfaction with family life.

2. The Family Life Satisfaction by Adjectives Scale (FSAS). This scale was developed by Barraca et al. (2000). The FSAS consists of 27 items representing a variety of adjectives which reflect the different emotions evoked by the family. The Portuguese version of the FSAS was used, which has evidenced adequate psychometric characteristic in Portugal (Nave, Jesús, Barraca, \& Parreira, 2006). In the current study, Cronbach's alpha was 0.95 .

3. Satisfaction with Life Scale (SWLS). The SWLS (Diener et al., 1985) includes five items to assess overall cognitive judgments about an individual's own life. (e.g., "If I could live my life over, I would change
Table 1 Intercorrelations among the SWFLS items and factor loadings

\begin{tabular}{|c|c|c|c|c|c|c|}
\hline \multirow[t]{2}{*}{ Items } & \multicolumn{5}{|c|}{$\begin{array}{l}\text { Intercorrelations among } \\
\text { the items }\end{array}$} & \multirow[t]{2}{*}{$\begin{array}{l}\text { Factor } \\
\text { loadings }\end{array}$} \\
\hline & 1 & 2 & 3 & 4 & 5 & \\
\hline $\begin{array}{l}\text { 1. In most ways my family life } \\
\text { is close to my ideal. }\end{array}$ & - & & & & & 0.82 \\
\hline $\begin{array}{l}\text { 2. The conditions of my family } \\
\text { life are excellent. }\end{array}$ & $0.65^{*}$ & - & & & & 0.83 \\
\hline $\begin{array}{l}\text { 3. I am satisfied with my } \\
\text { family life. }\end{array}$ & $0.78^{*}$ & $0.79^{*}$ & - & & & 0.94 \\
\hline $\begin{array}{l}\text { 4. So far I have gotten the } \\
\text { important things I want in } \\
\text { my family life. }\end{array}$ & $0.72^{*}$ & $0.68^{*}$ & $0.78^{*}$ & - & & 0.83 \\
\hline $\begin{array}{l}\text { 5. If I could live my family } \\
\text { life over, I would change } \\
\text { almost nothing. }\end{array}$ & $0.63^{*}$ & $0.62^{*}$ & $0.67^{*}$ & $0.60^{*}$ & - & 0.71 \\
\hline
\end{tabular}

almost nothing"). The responses range from one (strongly disagree) to seven (strongly agree). Greater values indicate higher satisfaction with life. The SWLS has good internal consistency and test-retest reliability (Pavot \& Diener, 1993). It contains no items that assess affect (Pavot \& Diener, 2008). The Portuguese-

language version of the SWLS was used, which has evidenced adequate psychometric characteristics in past research in Portugal (Munoz Sastre, Vainsonneau, Neto, Girard, \& Mullet, 2003; Neto, 1993; Neto et al., 1990). In the present study, Cronbach's alpha was 0.83 .

4. Self-esteem. To assess self-esteem, a single-item measure was used ("I am someone who generally has high self-esteem") (Neto \& Fonseca, 2018; Robins, Hendin, \& Trzesniewski, 2001). The responses range from 1 (not at all) to 5 (very much). This measure is valid (Robins et al., 2001) and proxy for the ten-item Rosenberg's (1965) scale.

5. Loneliness. The brief version of the Revised UCLA Loneliness Scale was used (Neto, 1992, 2014; Russell, Peplau, \& Cutrona, 1980). This scale (ULS-6) includes six items (e. g., "People are around me but not with me"). The items are answered on a four-point scale from one (never) to four (often). This scale was previously developed in the Portuguese culture (Neto, 1992, 2014). In the current study, Cronbach's alpha was 0.81 .

6. Multidimensional Scale of Perceived Social Support (MSPSS). The MSPSS was developed by Zimet, Dahlem, Zimet, and Farley (1988). It is a self-report measure that evaluates the social support in three domains: family (FA), one example item is "My family really tries to help me"; friends (FR), one example item is "I can talk about my problems with my friends"; and significant others (SO), one example item is "There is 
a special person who is around when I am in need." Respondents answered on a scale from one (strongly disagree) to seven (strongly agree). The reliability and validity of the MSPSS have been demonstrated across several groups (Canty-Mitchell \& Zimet, 2000). In the current study, the Portuguese version of MSPSS, adapted by Carvalho, Pinto-Gouveia, Pimental, Maia, and Mota-Pereira (2011), was used. High scores indicate high levels of perceived social support. Cronbach alpha coefficients for the present study, for the total scale, family support, friends support, and significant others support were $0.92,0.94,0.92$, and 0.92 , respectively.

7. Demographics. The demographic survey included items concerning age, gender, parents' level of education, and school year.

\section{Procedure}

In developing the Portuguese version of the SWFLS, the guidelines proposed in the literature on cross-cultural methodology were followed (Brislin, 2000): independent/ blind/back-translation, educated translation, and smallscale pretests. The second author initially translated the SWFLS into Portuguese, and this version was then translated back into English by a translator unaffiliated with the research. The two translators then solved minor discrepancies that appeared through the back-translation process. In addition, three faculty members in psychological assessment examined the preliminary form regarding the items' meaning. Finally, the scale was tested by giving it to 15 adolescents, who did not have any difficulty in understanding the meaning of the items.

Initially, contacts were made with the DRELVT (Regional Direction of Education of Lisbon and Vale do Tejo) via electronic mail, in order to obtain the necessary authorizations for the application of questionnaires in public schools in the district of Lisbon, where a positive answer was received. Subsequently, researchers met with the school board and the class directors to explain the goal of the study and how the data would be collected. After this meeting, a leaflet was distributed by all students, requiring the parents to authorize their students to participate in the study.

After collecting the signed authorizations, the questionnaires were applied to the students who agreed to participate in the study. Data were collected via paper-and-pencil, during May and June 2018, by a trained researcher. The anonymity of the participants was ensured. The questionnaire took approximately $20 \mathrm{~min}$ to complete.

\section{Data analyses}

Various data analyses were conducted, such as descriptive statistics, confirmatory factor analysis (CFA), reliability, analyses of variance (ANOVAs), Pearson product-moment correlations, and hierarchical multiple regressions. CFA was performed to assess the adequacy of the unidimensional model for the SWFLS. Regarding CFA diverse goodness-of-fit statistics, the goodness of fit index (GFI), comparative fit index (CFI), standardized root mean square residual (SRMR), and root mean square error of approximation (RMSEA) were evaluated. Cronbach's alpha was used to analyze the reliability of the scales. ANOVAs were used to evidence potential sociodemographic effects. To test for convergent and discriminant validity, bivariate Pearson's correlations between the SWFLS and various measures of wellbeing and psychological functioning were evaluated. Regression analyses were performed to examine whether the SWFLS adds incremental validity to FSAS. Data were mostly analyzed using the IBM SPSS statistics version 24, barring the CFA, for which Statistica (SEPATH) was used. The significance level set in the present study was $5 \%$.

\section{Quality criteria \\ Construct validity}

The construct validity was tested using confirmatory factor analysis. CFA was conducted on the raw data of the SWFLS to examine the established unidimensional model, with five items defined as indicators for one latent factor (Zabriske \& Ward, 2013; Zabriskie \& McCormick, 2003). The estimates of model fit were based on a maximum likelihood solution. No correlation between error terms was allowed. The $\chi^{2}$ statistic was $19.81(\mathrm{df}=5)$ with the $\chi^{2} / \mathrm{df}$ ratio having a value of 3.96, less than 5, which indicates an acceptable fit (Kline, 2005). Standardized factor loadings of the SWFLS were $=0.71-0.94$. All loadings were significant $(p<0.001)$ (see Table 1 ). The values of the fit indices were satisfactory $(\mathrm{GFI}=0.97, \mathrm{CFI}=0.99, \mathrm{SRMR}=0.02, \mathrm{RMSEA}=0.06)$ (Bentler, 1990). Regarding the diverse fit indexes of the current model, the data closely fit the hypothesized model. Therefore, these findings support the one-factor model among Portuguese adolescents.

\section{Reliability and descriptive statistics}

In order to assess the internal consistency of the SWFLS scores, Cronbach's coefficient alpha (Cronbach \& Shavelson, 2004) and item-total correlation for each item were performed. Cronbach's alpha (0.92) for satisfaction with family life score was excellent. The alpha coefficient of the remaining scale (when the item was removed) was 0.72 or above. The corrected itemtotal correlations showed values from 0.70 to 0.87 (see Table 2). The mean inter-item correlation coefficient was 0.69 . Thus, these findings provide good internal consistency for this sample.

Descriptive statistics of the SWFLS items are shown in Table 2. The average score of the SWLLS was 5.13. This 
Table 2 Psychometric properties of the Portuguese version of the Satisfaction with Family Life Scale

\begin{tabular}{|c|c|c|c|c|c|}
\hline Scale/item & M & SD & a & $a$ if scale item deleted & $\begin{array}{l}\text { Corrected item-total } \\
\text { correlations }\end{array}$ \\
\hline SWFLS & 5.13 & 1.42 & 0.92 & - & - \\
\hline 1. In most ways my family life is close to my ideal. & 4.98 & 1.65 & - & 0.89 & 0.79 \\
\hline 2. The conditions of my family life are excellent. & 5.25 & 1.57 & - & 0.89 & 0.77 \\
\hline 3. I am satisfied with my family life. & 5.4 & 1.54 & - & 0.87 & 0.87 \\
\hline 4. So far I have gotten the important things I want in family life. & 5.26 & 1.46 & - & 0.89 & 0.79 \\
\hline 5. If I could live my family life over, I would change almost nothing. & 4.75 & 1.97 & - & 0.72 & 0.7 \\
\hline
\end{tabular}

Note: $M$ Mean, SD Standard deviation, $a$ Cronbach's $a$

result indicates that satisfaction with family life is slightly high and above the neutral midpoint of $4.00(\mathrm{p}<0.01)$. As expected, boys $(M=5.16, S D=1.43)$ and girls $(M=5.09$, $S D=1.40),[F(1,251)=0.14, p=0.71]$ did not differ significantly on the SWFLS scores. The effect of age on family satisfaction scores was also not statistically significant, $[F(4,247)=1.10, p=0.36]$.

In sum, the SWFLS scores displayed satisfactory psychometric properties in this sample. Following this, the relationship between SWFLS scores and those of wellbeing and interpersonal functioning measures will be examined (Fig. 1).

\section{Convergent and discriminant validity}

In order to estimate the convergent validity of the SWFLS, one tool was also chosen to obtain a measure of family satisfaction. The selected instrument was the FSAS (Barraca et al., 2000). A significant correlation was found between the two instruments $(r=0.64, p<0.001)$.

An additional method used to obtain data about the validity was to estimate the relationships between the SWFLS scores and wellbeing and interpersonal functioning measures. As expected, there were strong significant positive correlations between the scores of the SWFLS, and life satisfaction $(r=0.65, p<0.001)$ and family support $(r=0.65, p<0.001)$. These findings support the convergent validity of the SWFLS.

Validity was also tested by conducting hierarchical multiple regression to explore whether the SWFLS adds incremental validity to the FSAS. Satisfaction with life was used as a criterion. Firstly, in block 1, satisfaction with life was regressed on the demographic factors (gender and age) (see Table 3). The $R^{2}$ of 0.00 was not significant: $F(2,248)=0.07, p=0.94$. Then, in block 2 , the FSAS was added to the model. The change in $R^{2}$ was 0.33: $F(3,247)=40.91, p<0.001$. Finally, in block 3, satisfaction with family life was added to the model. The change in $R^{2}$ was 0.14: $F(4,246)=54.94, p<0.001$.

Evidence for discriminant validity was demonstrated by small associations with variables such as self-esteem $(r=0.28, p<0.001)$, friends support $(r=0.21, p<0.001)$, and significant others support $(r=0.24, p<0.001)$. Significant negative correlation was observed between the scores of the SWFLS and loneliness $(r=-0.26, p<0.001)$. These results support the discriminant validity of the SWFLS.

\section{Discussion}

The present study provided support for the utility of the SWFLS as a measure of overall satisfaction with one's family. The reported findings on the Portuguese version of the Satisfaction with Family Life Scale provided support for its construct validity, the reliability of the measure, and the convergent and discriminant validities. Indices of reliability and validity met acceptable standards of measurement.

The fit indices in the CFA showed acceptable fit for this young sample. The CFA displayed a one-factor solution of the scale. This factor structure is consistent with data from Australian, British, Canadian, New Zealand, US (Zabriske \& Ward, 2013), Chilean (Schnettler et al., 2017), and Peruvian samples (Caycho-Rodriguez et al., 2018).

With regard to reliability, the findings suggested that this Portuguese version of the SWFLS was internally consistent. The internal consistency was excellent. The item-total correlations and factor loadings pointed out that item number five is the weakest in terms of convergence with the other items. Zabriske and Ward (2013) showed the same finding which may be related to the fact that this item concerns primarily the past, whereas the other four items concern the present (Pavot \& Diener, 1993). The average score found was significantly above the neutral score, suggesting a norm of general satisfaction with life for the adolescents of this sample.

The relationships between the SWFLS and the sociodemographic variables were favorable. In particular, regarding the effect of gender on SWFLS scores, no significant differences were expected. This is, indeed, what the current study has found. This finding is in agreement with previous findings showing no relevant differences in life satisfaction between genders (Diener \& Ryan, 2009; Glaesmer et al., 2011; Myers \& Diener, 1995), and other domain satisfactions, such as love life satisfaction (Neto \& Pinto, 2015a; Neto \& Wilks, 2017), 

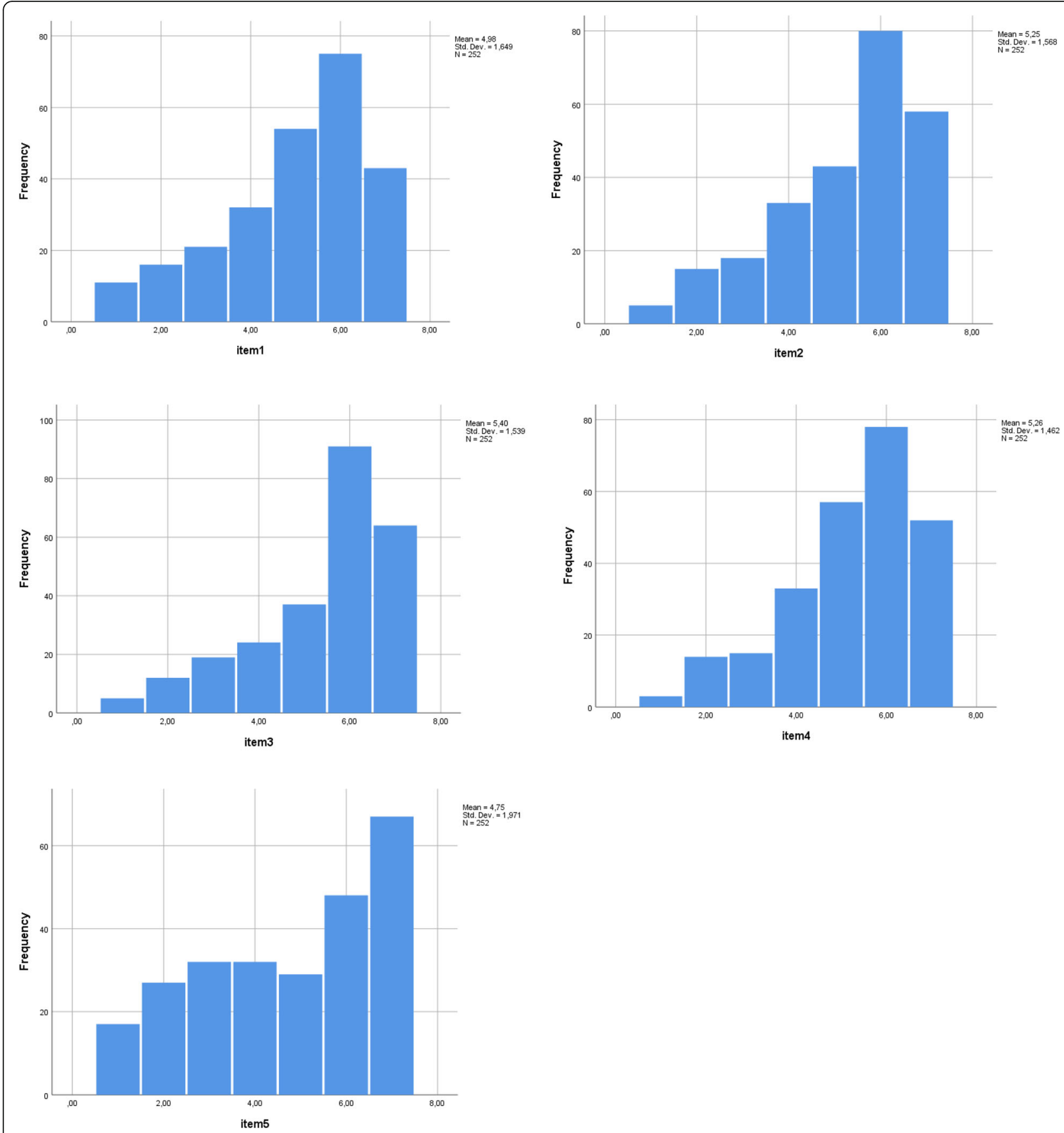

Fig. 1 Participants' responses to the items of the Satisfaction with Life Scale

satisfaction with sex life (Neto \& Pinto, 2015b), satisfaction with migration life (Neto \& Fonseca, 2016), and satisfaction with job life (Neto \& Fonseca, 2018). Similarly, the effect of age on SWFLS scores was not significant, which is consistent with previous results that found no relevant differences in life satisfaction among different age groups (Glaesmer et al., 2011; Myers \& Diener, 1995), and specific domains of life satisfaction (Neto \& Fonseca, 2016, 2018).
In addition, validity was supported by correlations with measures of wellbeing and current interpersonal functioning. Validity for the interpretation of scale scores was suggested by the correlation, in an appropriate way, with another family satisfaction measure (FSAS). The fact that satisfaction with family life is correlated with a measure of a variety of adjectives, which reflect different emotions evoked by the family, provides evidence of convergent validity for the SWFLS. 
Table 3 Hierarchical multiple regression of satisfaction with life onto demographic variables, FSAS, and satisfaction with family life

\begin{tabular}{|c|c|c|c|c|}
\hline \multirow[t]{2}{*}{ Variable } & Beta & $t$ & $p$ & $R^{2}$ change \\
\hline & \multicolumn{4}{|c|}{ Satisfaction with life } \\
\hline Block 1 & & & & $\begin{array}{l}0.00 ; F(2,248)=0.07 \\
p=0.94\end{array}$ \\
\hline Gender & 0.02 & 0.31 & 0.75 & \\
\hline Age & 0.01 & 0.19 & 0.85 & \\
\hline Block 2 & & & & $\begin{array}{l}0.33 ; F(3,247)=40.91, \\
p<0.001\end{array}$ \\
\hline FSAS & 0.58 & 11.97 & $<0.001$ & \\
\hline Block 3 & & & & $\begin{array}{l}0.14 ; F(4,246)=54.94, \\
p<0.001\end{array}$ \\
\hline $\begin{array}{l}\text { Satisfaction } \\
\text { with family life }\end{array}$ & 0.49 & 8.07 & $<0.001$ & \\
\hline
\end{tabular}

The SWFLS scores correlated strongly with life satisfaction and family support, demonstrating the convergent validity of the scale. Past research has also shown strong relationships between life satisfaction and domains of life satisfaction (Ruiz et al., 2009). Higher levels of satisfaction with family relationships were associated with higher overall life satisfaction (Schimmack et al., 2002; Schnettler et al., 2017). Past research indicated that greater social support was linked to greater levels of life satisfaction (Goodwin \& Hernandez, 2000; Kong, Zhao, \& You, 2012).

Current findings are consistent with the "bottom-up" approach to satisfaction with family life (Brief et al., 1993), reflecting the relevance of family relations as a source of satisfaction with life (Schimmack et al., 2002). The two measures of family satisfaction used explained $47 \%$ of the variance in life satisfaction. Furthermore, the SWFLS, a cognitive component, added significant variance to the FSAS, a primarily emotional component, to explain life satisfaction. These results suggest that both instruments are complementary to assess family satisfaction.

Finally, four indicators for the discriminant validity of the SWFLS were evaluated. The SWFLS scores showed moderate positive correlations with self-esteem, friends support, and significant others support, as well as moderate negative correlation with loneliness. It is worth noting that the relation between family satisfaction, and friends support and significant others support was smaller than the relation between family satisfaction and family support. These moderate correlations supported the discriminant validity of the SWFLS.

This study has several limitations. First, a convenience sample including only adolescents was recruited. Future research should include a more diverse age range. Second, the study fully relies on self-reported questionnaires. Future research should include structured interviews in order to rule out the possibility of method biases. Third, the cross-sectional design of this work does not allow to test causal relations of family satisfaction with the other variables.

In spite of these limitations, we have considered it useful to share this Portuguese adaptation with other researchers with interest in the field of family relations, hoping that it will stimulate further investigation in this area. Namely, it suggests the usability of the SWFLS in Portuguesespeaking populations. The SWFLS would appear to have some advantages over other family evaluation tools. In its brief five-item format, the SWFLS affords an expedient way to assess the overall cognitive satisfaction a person has obtained from his or her family.

\section{Acknowledgements}

Not applicable.

Authors' contributions

The authors contributed equally to the construction of this article. All authors read and approved the final manuscript.

Funding

Not applicable. This study had no funding in the design of the study, data collection, analysis, and interpretation and in the writing of the manuscript

Availability of data and materials

Not applicable. The dataset supporting the conclusions of this article will not be shared, all available data is included within the article.

\section{Competing interests}

The authors declare that they have no competing interests.

Received: 20 November 2018 Accepted: 1 July 2019

Published online: 26 July 2019

\section{References}

Bardo, A. R., \& Yamashita, T. (2014). Validity of domain satisfaction across cohorts in the US. Social Indicators Research, 117, 367-385. https://doi.org/10.1007/ s11205-013-0351-6.

Barraca, J., Yarto, L. L., \& Olea, J. (2000). Psychometric properties of a new family life satisfaction scale. European Journal of Psychological Assessment, 16, 98106. https://doi.org/10.1027//1015-5759.16.2.98.

Bendayan, R., Blanca, M., Fernández-Baena, J., Escobar, M., \& Trianes, M. (2013). New empirical evidence on the validity of the Satisfaction with Life Scale in early adolescents. European Journal of Psychological Assessment, 29, 36-43. https://doi.org/10.1027/1015-5759/a000118

Bentler, P. (1990). Comparative fit indexes in structural models. Psychological Bulletin, 107, 238-246. https://doi.org/10.1037/0033-2909.107.2.238.

Brief, A. P., Butchner, A. H., George, J. M., \& Link, K. E. (1993). Integrating bottomup and top-down theories of subjective well-being: The case of health. Journal of Personality and Social Psychology, 64(4), 646-653. https://doi.org/1 0.1037/0022-3514.64.4.646.

Brislin, R. W. (2000). Some methodological concerns in intercultural and cross-cultural research. In R. W. Brislin (Ed.), Understanding culture's influence on behaviour (2nd ed., pp. 349-411). Fort Worth: Harcourt.

Canty-Mitchell, J., \& Zimet, G. D. (2000). Psychometric properties of the Multidimensional Scale of Perceived Social Support in urban adolescents. American Journal of Community Psychology, 28(3), 391-400. https://doi.org/1 0.1023/A:1005109522457.

Carvalho, S., Pinto-Gouveia, J., Pimental, P., Maia, D., \& Mota-Pereira, J. (2011). Características psicométricas da versão portuquesa da Escala Multidimensional de Suporte Social Percebido (Multidimensional Scale of Perceived Social SupportMSPSS) (Vol. 54, pp. 309-358). Psychologica. https://doi.org/10.14195/1647-86 06_54_13.

Caycho-Rodriguez, T., et al. (2018). Validez e invarianza factorial de una medida breve de Satisfacción com la Vida Familiar. Universitas Psychologica, 17(5), 1-17. 
Cronbach, L., \& Shavelson, R. (2004). My current thoughts on coefficient alpha and successor procedures. Educational and Psychological Measurement, 64 391-418. https://doi.org/10.1177/0013164404266386.

Diener, E., Inglehart, R., \& Tay, L. (2013). Theory and validity of life satisfaction scales. Social Indicators Research, 112, 497-527. https://doi. org/10.1007/s11205-012-0076-y.

Diener, E., Oishi, S., \& Lucas, R. (2003). Personality, culture, and subjective well-being: emotional and cognitive evaluations of life. Annual Review of Psychology, 54, 403425. https://doi.org/10.1146/annurev.psych.54.101601.145056.

Diener, E., Oishi, S., \& Lucas, R. (2015). National accounts of subjective well-being. American Psychologist, 70, 234-242. https://doi.org/10.1037/a0038899.

Diener, E., \& Ryan, K. (2009). Subjective well-being: A general overview. South African Journal of Psychology, 39, 391-406. https://doi.org/10.1177/ 008124630903900402.

Diener, E., Sandvik, E., Seidlitz, L., \& Diener, M. (1993). The relationship between income and subjective well-being - relative or absolute. Social Indicators Research, 28, 195-223. https://doi.org/10.1007/BF01079018.

Diener, E. R., Emmons, R., Larsen, R., \& Griffin, S. (1985). The Satisfaction with Life Scale. Journal of Personality Assessment, 49, 71-75. https://doi.org/10.1207/ s15327752jpa4901_13.

Glaesmer, H., Grande, G., Braehler, E., \& Roth, M. (2011). The German version of the Satisfaction with life scale (SWLS). European Journal of Psychological Assessment, 27(4), 127-132. https://doi.org/10.1027/1015-5759/a000081.

Goodwin, R., \& Hernandez, S. (2000). Perceived and received social support in two cultures: collectivism and support among British and Spanish students. Journal of Social and Personal Relationships, 17, 282-291. https://doi.org/10.11 77/0265407500172007.

Kline, P. (2000). The handbook of psychological testing (2nd ed.). London: Routledge.

Kline, R. B. (2005). Principles and practice of structural equation modeling (2nd ed.). New York: Guilford.

Kong, F., Zhao, J., \& You, X. (2012). Emotional intelligence and life satisfaction in Chinese university students: The mediating role of self-esteem and social support. Personality and Individual Differences, 53(8), 1039-1043. https://doi. org/10.1016/j.paid.2012.07.032.

Munoz Sastre, M. T., Vainsonneau, G., Neto, F., Girard, M., e Mullet, E. (2003). Forgiveness and satisfaction with life. Journal of Happiness Studies, 4(3), 323-335.

Myers, D. G., \& Diener, E. (1995). Who is happy? Psychological Science, 6, 10-19. https://doi.org/10.1111/j.1467-9280.1995.tb00298.x.

Nave, F., Jesús, S., Barraca, J., \& Parreira, P. (2006). Adaptation of the Family Satisfaction by Adjectives Scale (FSAS) to Portuguese population. Ansiedad Y Estrés, 13, 111-120.

Neto, F. (1992). Loneliness among Portuguese adolescents. Social Behavior and Personality, 20(1), 15-22. https://doi.org/10.2224/sbp.1992.20.1.15.

Neto, F. (1993). Satisfaction with Life Scale: psychometric properties in an adolescent sample. Journal of Youth and Adolescence, 22(2), 125-134. https:// doi.org/10.1007/BF01536648

Neto, F. (2005). The Satisfaction with Love Life Scale. Measurement and Evaluation in Counseling and Development, 38, 2-13. https://doi.org/10.1 080/07481756.2005.11909765.

Neto, F. (2012). The Satisfaction with Sex Life Scale. Measurement and Evaluation in Counseling and Development, 45, 18-31. https://doi.org/10.1177/07481 75611422898.

Neto, F. (2014). Psychometric analysis of the short-form UCLA Loneliness Scale (ULS-6) in older adults. European Journal of Ageing, 11(4), 313-319. https:// doi.org/10.1007/s10433-014-0312-1.

Neto, F., Barros, J., \& Barros, A. (1990). Satisfação com a vida. In L. Almeida, R. Santiago, P. Silva, L. Oliveira, O. Caetano, \& J. Marques (Eds.), A acção educativa: Análise psico-social (pp. 91-100). Leiria: ESEL./APPORT.

Neto, F., \& Fonseca, A. C. (2016). The Satisfaction with Migration Life Scale. International Journal of Intercultural Relations, 54, 47-54. https://doi.org/10.1 016/j.jijintrel.2016.07.004.

Neto, F., \& Fonseca, A. C. (2018). The Satisfaction with Job Life Scale among Immigrants. Psychological Studies, 63(3), 209-218. https://doi.org/10.1007/ s12646-018-0449-7.

Neto, F., \& Pinto, M. C. (2015a). Satisfaction with love life across the adult life span. Applied Research in Quality of Life, 10, 289-304. https://doi.org/10.1007/ s11482-014-9314-6.

Neto, F., \& Pinto, M. C. (2015b). A cross-cultural investigation of satisfaction with sex life among emerging adults. Social Indicators Research, 120, 545-557. https://doi.org/10.1007/s11205-014-0604-z.
Neto, F., \& Wilks, D. (2017). Predictors of psychological adaptation of Cape Verdean students in Portugal. Journal of College Student Development, 58(7), 1087-1099. https://doi.org/10.1353/csd.2017.0085.

Pavot, W., \& Diener, E. (1993). Review of the satisfaction with life scale. Psychological Assessment, 5(2), 164-172. https://doi.org/10.1037/1040-35 90.5.2.164.

Pavot, W., \& Diener, E. (2008). The satisfaction with life scale and the emerging construct of life satisfaction. The Journal of Positive Psychology, 3, 137-152. https://doi.org/10.1080/17439760701756946

Poff, R. A., Zabriskie, R. B., \& Townsend, J. A. (2010). Modeling family leisure and related family constructs: A national study of US parent and youth perspectives. Journal of Leisure Research, 42(3), 365-391. https://doi.org/10.1 080/00222216.2010.11950210.

Robins, R. W., Hendin, H. M., \& Trzesniewski, K. H. (2001). Measuring global selfesteem: Construct validation of a single measure and the Rosenberg selfesteem scale. Personality and Social Psychology Bulletin, 27, 151-161. https:// doi.org/10.1177/0146167201272002.

Rosenberg, M. (1965). Society and the adolescent self-image. Princeton: Princeton University Press.

Ruiz, F. (2010). Le bien-être subjectif chez des adultes Portugais. Paris: Doctoral dissertation : École Pratique des Hautes Études.

Ruiz, M. F., Neto, F., Munoz Sastre, M. T., Salvatore, N., Rivière, S., \& Mullet, E. (2009). Life domain satisfaction: A Portugal-France comparison. Social Indicators Research, 94, 173-181. https://doi.org/10.1007/s11205-008-9359-8.

Russell, D., Peplau, L., \& Cutrona, C. (1980). The revised UCLA Loneliness Scale: Concurrent and discriminant validity evidence. Journal of Personality and Social Psychology, 39, 472-480. https://doi.org/10.1037/0022-3514.39.3.472.

Schimmack, U., Diener, E., \& Oishi, S. (2002). Life-satisfaction in a momentary judgment and a stable personality characteristic: The use of chronically accessible and stable sources. Journal of Personality, 70, 345-384. https://doi. org/10.1111/1467-6494.05008.

Schnettler, B., Miranda-Zapata, E., Grunert, K. G., Lobos, G., Denegri, M., Hueche, C., \& Poblete, H. (2017). Life satisfaction of university students in relation to family and food in a developing country. Frontiers in Psychology, 8, 1522. https://doi.org/10.3389/fpsyg.2017.01522.

Shin, D. C., \& Johnson, D. M. (1978). Avowed happiness as an overall assessment of the quality of life. Social Indicators Research, 5, 475-492. https://doi.org/1 $0.1007 / B F 00352944$

Vallerand, R. J., \& Boissonnette, R. (1990). Construction et validation de l'Échelle de Satisfaction dans les Études. Canadian Journal of Behavioral Science, 22(3), 295-306. https://doi.org/10.1037/h0078987.

Zabriske, R. B., \& Ward, P. (2013). Satisfaction with Family Life Scale. Marriage \& Family Review, 49, 446-463. https://doi.org/10.1080/01494929.2013.768321.

Zabriskie, R., \& McCormick, B. (2003). Parent and child perspectives of family leisure involvement and satisfaction with family life. Journal of Leisure Research, 35(2), 163-189. https://doi.org/10.1080/00222216.2003.11949989.

Zimet, G. D., Dahlem, N. W., Zimet, S. G., \& Farley, G. K. (1988). The Multidimensional Scale of Perceived Social Support. Journal of Personality Assessment, 52(1), 30-41. https://doi.org/10.1207/s15327752jpa5201_2.

\section{Publisher's Note}

Springer Nature remains neutral with regard to jurisdictional claims in published maps and institutional affiliations.

Ready to submit your research? Choose BMC and benefit from:

- fast, convenient online submission

- thorough peer review by experienced researchers in your field

- rapid publication on acceptance

- support for research data, including large and complex data types

- gold Open Access which fosters wider collaboration and increased citations

- maximum visibility for your research: over $100 \mathrm{M}$ website views per year

At BMC, research is always in progress.

Learn more biomedcentral.com/submissions 